УДК 553.31

\title{
ХАРАКТЕРИСТИКА РУД ЛИСАКОВСКОГО МЕСТОРОЖДЕНИЯ С ЦЕЛЬЮ ИХ КОМПЛЕКСНОЙ ПЕРЕРАБОТКИ
}

\author{
Каскатаева Куралай Балапашовна ${ }^{1}$, \\ aigakk@mail.ru
}

\author{
Кряжева Татьяна Владимировна ${ }^{1}$, \\ kryazheva_@mail.ru
}

Садчиков Александр Викторович1, a.sadchikov@kstu.kz

\author{
Дьяконов Виктор Васильевич², \\ mdf.rudn@mail.ru
}
1 Некоммерческое акционерное общество «Карагандинский технический университет», Казахстан, 100027, г. Караганда, пр. Н. Назарбаева, 56.
2 Российский государственный геологоразведочный университет им. Серго Орджоникидзе (МГРИ), Россия, 117997, г. Москва, ул. Миклухо-Маклая, 23.

\begin{abstract}
Актуальность исследования обусловлена необходимостью оценки возможности попутного извлечения цветных, редких металлов и рассеянных элементов. В основу исследования положены результаты анализа проб оолитовых руд с западного участка месторождения. В ходе проведения научно-исследовательских работ изучаются промышленные типы железных руд месторождения, рассматривается распределение редких металлов по различным промышленным типам, фрракциям лисаковских железных руд и концентратам.

Цель: изучение характеристик руд Лисаковского месторождения с целью их комплексной переработки.

Объект: оолитовые руды Лисаковского месторождения.

Методика. Проведены лабораторные исследования руд и концентратов Лисаковского месторождения. Проведен гранулометрический анализ руд по типам и сортам. Изучен химический состав руд и концентратов по фрракциям.

Результаты. Исследования гранулометрического состава руд показывают, что руды I и II сорта состоят в основном (до 80 \%) из фрракции -0,63+0,16 мм. В руде III сорта количество основных фрракций понижается до 60 \%, а количество фрракций $+0,63$ и -0,16 мм повышается суммарно до $40 \%$. Анализ результатов лабораторных исследований проб из хвостов обогащения показал, что содержания металлов: Sr, Ti, Zr, Ga, Ce, Ba, Be, Li, Cd, Y u Co, ниже кларкового значения в литосфере. Coдержания $\mathrm{Mn}, \mathrm{Pb}, \mathrm{As}, \mathrm{W}, \mathrm{Cr}, \mathrm{Ni}, \mathrm{Bi}, \mathrm{Mo}, \mathrm{V}, \mathrm{Cu}$ выше среднего значения содержания металлов в литосфере. Так, содержания Cu, $\mathrm{Ag}$ и W превышают кларковые содержания в 5, 9 и 12,5 раз, а содержания Mn, Pb и Bi превышают средние значения в 33,55 и 59 раз.
\end{abstract}

\section{Ключевые слова:}

Продуктивная толща, оолиты, типы руд, фразовый состав, минеральный состав,

внутреннее строение оолитов, концентрат, гранулометрический состав, химический состав.

\section{Введение}

Лисаковсское железорудное месторождение является градообразующим для г. Лисаковск, который расположен на правом берегу р. Тобол в Костанайской области. Месторождение находится в 20 км южнее железнодорожной станции Тобол. Запасы руды, с утвержденными в ГКЗ, оценены: по категориям $\mathrm{A}+\mathrm{B}+\mathrm{C} 1$ со средним содержанием железа $35,4 \%$ и составляют 1728,2 млн т и по категории С2 со средним содержанием железа 25,56 \% и составляют 1158,36 млн т. Забалансовые руды со средним содержанием железа 25,56 \% составляют 3031,6 млн т.

Руды содержат $0,071 \%$ серы и $0,64 \%$ фосфора, залегают на небольшой глубине. Добыча производится с минимальным количеством взрывных работ [1-5].

Для изучения промышленных типов нами отобраны пробы оолитовых руд с западной части месторождения.

\section{Общие сведения}

Геологоразведочными работами было установлено, что руды месторождения приурочены к речной па- леодолине, имеющей возраст среднего олигоцена. Процессы, протекающие во время стадии седиментации и раннего диагенеза, играют основную роль в образовании оолитов, а в стадию позднего диагенеза совершаются главным образом процессы дегидратации, усыхания, синерезиса и перекристаллизации минерального вещества. В стадию седиментации в речных условиях, в окислительной геохимической обстановке формируются осадки, выпадающие из коллоидных растворов: коагуляты и коагели $\mathrm{Fe}(\mathrm{OH})_{3}, \mathrm{~A} 1(\mathrm{OH})_{3}$, $\mathrm{MnO}_{2}, \mathrm{SiO}_{2}$ и др., которые в разных условиях среды образуют оолиты, бобовины, сгустки, агрегаты и хлопьевидные массы.

Долина реки Праторгай простирается в широтном направлении, с запада на восток, от западного борта Тургайского прогиба к его осевой части. Она выполнена рыхлыми отложениями, представленными: галечниками, гравием, разнозернистыми, крупно-, средне- и мелкозернистыми кварцевыми песками с железистыми оолитами или лишенными их, алевритами, песчанистыми глинами, а также гидрогетито- 
выми и гидрогетито-сидерито-хлоритовыми оолитовыми рудами [2].

Исследованиями, проведенными в 2017-2019 гг., выявлено, что руды представлены тремя типами, имеющими близкий минеральный, химический и фазовый состав [3]. Следует отметить повышенное содержание вредной примеси пятиокиси фосфора до $1,19 \%[3]$.

Залежи западной части месторождения, вошли в состав рудной базы Лисаковского ГОКа. Здесь отмечены Главная, Южная, Степная и Восточная группы залежей. 75 \% основных запасов месторождения сосредоточены в западной части Главной залежи, имеющей протяженность в 21 км. Здесь сосредоточено до $50 \%$ запасов балансовых руд (в количестве 317 млн т со средним содержанием железа 39,2 \%), которые разрабатываются на участках № 2 и 3.

На месторождении выделяется 26 рудных залежей, разделённых между собой условными границами. Разрабатывается главная залежь (участки 1, 2, 3) со среднемассовой долей железа 38,2 \%, мощность уступов 12-13 м. Массовая доля железа в рудах колеблется в широком диапазоне - от 14,4 до 48 \% - при средней массовой долей серы $0,03 \%$ и фосфора до 0,7 \%. Мощность вскрыши 1-2 м в центральной части и до 20 м на периферии.

По составу руды гидрогетитовые, гидрогетитосидерито-хлоритовые и гидрогетит-лептохлоритовые Руда легко измельчается. Первые развиты в песках, песчаниках и гравийно-галечных отложениях речных русел и отчасти озер. Второй тип относится к аллювиально-пролювиальным и встречаются на террасах палеодолины. Третий обнаружен в озерно-болотных, старичных и отчасти в русловых отложениях под покровом глинистых пород, предохранивших руды от окисления [4].

\section{Типы железных руд Лисаковского месторождения}

Лисаковское месторождение характеризуется наличием трех типов железных руд, которые добываются в карьере на трёх различных участках.

Оолитовые лисаковские руды крупностью 0,2-0,6 мм представлены в основном гидрогетитом, размер которого менее 0,04 мм. Руда залегает неглубоко, добыча ее производится с незначительной крышей. Оолитовая структура руды позволяет производить добычу без взрывных работ и использовать ее в дальнейшем переделе без дробления.

Изучение руды Лисаковского месторождения под электронным микроскопом показывает, что в оолитах руды главная рудообразующая роль принадлежит гидрогетиту. Гидрогетит образует зерна в виде микроагрегатов размером 5-7 мкм. Здесь мы находим оолитовые, корковые, плитчатые, сплошные, конкреционные и жеодистые, а также охристые порошковатые его образования.

Исходным материалом для образования гидрогетитовых оолитов служили: а) коллоидные частицы гидрата окиси железа, с примесью окислов алюминия, марганца, коллоидные частицы кремнезема и т. д.; б) электролиты, подвергавшиеся в растворах диссо- циации, с образованием различных ионов $\left(\mathrm{Ca}^{+2}, \mathrm{Mg}^{+2}\right.$, $\mathrm{K}^{+}, \mathrm{Na}^{+}, \mathrm{Cl}^{-}$и др.); в) механические частицы - зерна кварца, иногда полевого шпата, гидрогетита, обломки расколовшихся железистых оолитов и бобовин, вторичные агрегаты и сгустки коагулятов гидрата окиси железа и других веществ.

Оолиты имеют округлую или неправильно округлую форму, окрашены в желтовато-бурый, бурый или темно-бурый, почти черный, цвет. Внешняя поверхность обладает полуметаллическим или матовым блеском.

Оолиты, обладающие концентрически зональным строением, содержат в себе центральные ядра, вокруг которых происходило наслоение коллоидальных частиц гидроокислов железа. Ядрами в оолитах служат песчинки кварца, гидрогетита, полевого шпата, обломки расколовшихся оолитов и т. д.

В нижних горизонтах рудной толщи, кроме гидрогетита, в составе цемента встречаются лептохлориты и частично сидерит. В составе некоторых оолитов вместе с гидрогетитом присутствует стильпносидерит. Содержание железа в оолитах 51,25 \%. В составе гидрогетита находится 34,3-34,4 \%, а в силикатах 7,7-8,2 \% трёхвалентного железа, двухвалентное железо не обнаружено [2].

Кварц широко распространен в составе рудной толщи. Он представлен обломочными зернами, гравием и гальками, которые в неодинаковом количестве встречаются в разных слоях оолитовых железняков. Крупность зерна - 1+0,03 мм.

На месторождении хлориты слагают главным образом цемент в оолитовых рудах и в песчаниках. В них можно увидеть отдельные скопления коагулятов, состоящих из зеленой лептохлоритовой минеральной массы.

Устойчивым классом крупности руд является фракция руд $-1+0,28$ мм. Класс $+0,074$ мм в основном представлен железистыми алюмосиликатами, количество которых составляет 73,3-85,5\%.

\section{Результат лабораторных исследований}

Детальные анализы результатов макро- и микроскопического, рентгенографического, электронномикроскопического, микрозондового и других видов исследований показывают, что основными структурными элементами в железных рудах месторождения являются оолиты, сцементированные зелено-цветной лептохлоритовой минеральной массой.

Результаты проведенных исследований показывают, что строение, минеральный состав, цвет, размер и форма оолитов различаются. Эти различия разных типов оолитов, по-видимому, являются отражением условий их образования и последующих преобразований, произошедших уже в сформировавшейся оолитовой породе.

Рыхлые оолитовые руды содержат в основном гидрогетит, гетит, кварц, феррихлорит; глинистые вещества, реже карбонаты, калиевые полевые шпаты; изредка в виде единичных включений встречаются зерна магнетита, мартита, пирита, гематита, биотита, серицита, глауконита, плагиоклаза, роговой обманки, 
эгирина, эпидота, апатита, циркона, мусковита, турмалина.

В рудах наблюдается несколько форм гидрогетита: оолиты, конкреции, плитки и аморфные порошковатые образования (охра).

Составной частью оолитов является гидрогетит двух генераций с тонкодисперсной примесью феррихлоритового и глинистого вещества. Гидрогетит первой генерации плотный темно-бурого цвета образует зерна, которые просматриваются лишь под электронным микроскопом в виде микроагрегатов размером до 5-7 мкм. Оолиты трещиноваты, поэтому слабо сопротивляются измельчению. Оолиты, сложенные таким гидрогетитом, с поверхности имеют металлический блеск. Строение оолитов преимущественно сплошное, реже концентрическое, форма округлая, реже овальная и эллипсоидальная. Магнетит редок и представлен тонкими кристаллическими частицами мельче 0,0050 мм, часто окислен до мартита. Размеры оолитов колеблются от 0,05 до 0,66 мм, преобладают $0,18-0,60$ мм.

Массовая доля железа в гидрогетите этой генерации составляет 53,5\%.

Гидрогетит второй генерации красновато-бурого и бурого цвета. Оолиты, сложенные таким гидрогетитом, имеют концентрическое и концентрически-зональное строение и содержат в себе центральные ядра, выполненные гидрогетитом, иногда кварцем, изредка полевым шпатом и др. Размер таких оолитов изменяется от 0,10 до 1,0 мм, преобладают от 0,2 до 0,37 мм.

Особенностью минерального состава этих руд является то, что в оолитах ферриалюмосиликаты диспергированы в гидрогетит, а в цементной части присутствует охристый гидрогетит, цементирующий оолиты и кварц. Массовая доля железа в таком гидрогетите составляет $62,8 \%$. Многие оолиты сильно изменили свое концентрически-зональное строение за счет растворения и перемещения железа внутри оолитов и при выносе железа из них, поэтому массовая доля железа в таких оолитах в среднем составляет 51,5\%.

Феррихлорит под микроскопом наблюдается в виде аморфной, изотропной или метаколлоидной массы от светло- до темно-зеленого цвета. Хлорит принадлежит к типу шамозита, он содержит магний и двухвалентное железо. В оолитовых рудах и рудных песчаниках феррихлориты слагают в основном цемент. В них можно видеть отдельные скопления, состоящие из зеленой феррихлоритовой массы. Формирование феррихлоритов происходило в окислительновосстановительной обстановке в ассоциации с сидеритом. Находясь в этих условиях и подвергаясь процессам выветривания, феррихлорит желтеет, буреет, обохривается и замещается бурыми гидроокислами железа, что наблюдается в охристо-феррихлоритогидрогетитовой разновидности [1-5].

Карбонаты встречаются в рудах второго и третьего горизонтов и представлены сидеритом в виде оторочек на сферолитовых зернах $(0,02-0,15$ мм) буроватого цвета. На некоторых участках залежей в рудах встречается сидерит в массивной форме, обладающий повышенной магнитной восприимчивостью за счет включений тонкорассеянного магнетита. В очень незначительном количестве на отдельных участках встречается кальцит, выполняющий микротрещинки в зернах калиевых полевых шпатов.

Сидерит часто нарастает на гидрогетитовых или гидрогетито-хлоритовых оолитах в виде внешних оторочек. Такие же оторочки сидерита мы видим иногда на кварцевых зернах и на расколовшихся обломках оолитов.

Кальциевый фосфат относится к группе апатита, его молекула может содержать одну или несколько групп ОН и, возможно, немного $\mathrm{SiO}_{2}$ вместо $\mathrm{PO}_{4}$. Его морфология может быть различной - аморфной и псевдогексагональной.

Калиевые полевые шпаты встречаются почти во всех пробах в виде корродированных изометричных зерен (0,05-0,35 мм) буроватого цвета, трещиноватых, в различной степени пелитизированных и хлоритизированных. По трещинкам развивается гидрогетит, серицит, кальцит. В некоторых зернах калиевого полевого шпата наблюдаются включения апатита, турмалина, циркона.

Глина в цементе руд представлена в основном пелитовой массой серого и буровато-серого цвета, состоящей из тонкочещуйчатого каолинита в смеси с феррихлоритом и дисперсным гидрогетитом. В рудах второго и третьего горизонтов встречаются гнездообразные и массивные выделения глин с включениями тонкодисперсного магнетита. Глина интенсивно замещает калиевые полевые шпаты.

Кварц в рудах представлен обломочными зернами, иногда гравием и галькой, которые в неодинаковом количестве встречаются в разных слоях оолитовых и массивных руд. Имеются слои и прослойки кварцевых песков, содержащие оолиты. Размер зерен кварца изменяется от 0,02 до 1,37 мм. Зерна кварца слегка желтоватого цвета, иногда содержат включения апатита.

Концентрически-зональное строение оолитов хорошо наблюдается в полированных шлифах в отраженном свете.

Многие оолиты под воздействием позднего диагенеза и последующих процессов выветривания сильно изменились и утратили частично или полностью свое концентрически-зональное строение. Действия этих процессов проявились, с одной стороны, в раскристаллизации коагулятов, а с другой - в частичном растворении и перемещении железа внутри оолитов и в выносе железа из них $[1,2]$.

В одних случаях это приводило к срастанию соприкасавшихся оолитов, а в других, вообще, - к цементации гидроокислами железа оолитов, кварцевых зерен и другого пластического материала в данном слое.

Содержание кремнезема объясняется, с одной стороны, наличием в оолитах кварцевых песчинок, а с другой - вхождением в состав концентров коагулятов кремнезема, отрицательно заряженные коллоидные частицы которого, взаимодействуя в растворах с положительно заряженными коллоидными частицами гидрата окиси железа, коагулировали и осаждались, 
образуя тончайшие концентрические наслоения на концентрах гидроокислов железа. Растворение оолитов в соляной кислоте приводит иногда к сохранению кремнеземного скелета в осадке.

Глинозем в изучаемых оолитах не образует обособленных самостоятельных минералов. Повидимому, глинозем в оолитах входит в состав гидрогетитовых концентров в виде коагулятовой примеси алюмогеля (гидраргиллит-гель), осаждавшейся вместе с коллоидными частицами гидрата окиси железа, обладавшими положительными знаками электрического заряда.

В рудной толще, особенно в верхних и средних ее горизонтах, нередко встречаются прожилки, гнезда, корки, конкреции и жеоды, состоящие из гидрогетита а иногда из гидрогетита, гетита и лепидокрокита. Образование их связано частично с процессами разложения и окисления хлоритов и сидеритов, вторичные прожилки и гнезда которых наблюдаются местами в оолитовых железняках и песчаниках, где последние содержат включения растительных остатков. Частично же образование их связано с миграцией гидроокислов железа в коллоидных растворах. Гидрогематит встречается в рудной толще редко. Обычно он ассоциирует здесь с гидрогетитом, с которым образует прожилки и гнезда [2-7].

На примере участка № 1 проведен анализ фазового состава по железу структурно-минералогических разновидностей руд Лисаковского месторождения бурых железняков, результаты которого приведены в табл. 1 [3].

Таблица 1. Фазовый состав по железу структурно-минералогических разновидностей лисаковских руд

Table 1. Phase composition for iron of structural and mineralogical varieties of Lisakovsky ores

\begin{tabular}{|c|c|c|c|c|c|c|c|c|}
\hline \multirow{3}{*}{$\begin{array}{c}\text { Индекс, } \\
\text { Разновидности } \\
\text { Index, } \\
\text { Varieties }\end{array}$} & \multirow{3}{*}{$\begin{array}{c}\text { Удельная магнитная } \\
\text { восприимчивость, } \\
\mathrm{n} * 10^{8} \mathrm{~cm}^{2} / \text { кг } \\
\text { Specific magnetic susceptibility, } \\
\mathrm{n} * 10^{8} \mathrm{~cm}^{2} / \mathrm{kg}\end{array}$} & \multicolumn{3}{|c|}{$\begin{array}{l}\text { Содержание, \% } \\
\text { Content, \% }\end{array}$} & \multicolumn{4}{|c|}{$\begin{array}{c}\text { Распределение по фазам, \% } \\
\text { Phase distribution, \% }\end{array}$} \\
\hline & & \multirow{2}{*}{$\begin{array}{l}\mathrm{Fe}_{\text {общ }} \\
\mathrm{Fe}_{\text {gen }}\end{array}$} & \multirow[t]{2}{*}{$\mathrm{Fe}^{2+}$} & \multirow{2}{*}{$\begin{array}{l}\mathrm{Fe}_{\text {магн }} \\
\mathrm{Fe}_{\text {magn }}\end{array}$} & \multicolumn{2}{|c|}{$\begin{array}{c}\text { силикатное, в т. ч. } \\
\text { including silicate }\end{array}$} & \multirow{2}{*}{$\begin{array}{l}\mathrm{Fe}^{2+}{ }_{\text {карб }} \\
\mathrm{Fe}^{2+}{ }_{\text {carbo }}\end{array}$} & \multirow{2}{*}{$\begin{array}{l}\mathrm{Fe}^{3+}{ }_{\mathrm{ru}} \\
\mathrm{Fe}^{3+}{ }_{\mathrm{hi}}\end{array}$} \\
\hline & & & & & $\mathrm{Fe}_{\text {gen }}$ & $\mathrm{Fe}^{3+}$ & & \\
\hline Ч (черные) (black) & 36,74 & 44,6 & 0,71 & 0,06 & 6,80 & 6,80 & 0,69 & 37,07 \\
\hline Б (бурые) (brown) & 35,13 & 42,02 & 0,29 & 0,05 & 6,65 & 6,65 & 0,27 & 5,05 \\
\hline 3 (зеленые) (green) & 34,36 & 39,64 & 0,92 & 0,06 & 5,54 & 5,54 & 0,90 & 33,14 \\
\hline $\begin{array}{c}\text { Ж, } 3 \text { (желто-зеленые) } \\
\text { (yellow-green) }\end{array}$ & 36,85 & 43,32 & 0,45 & 0,06 & 6,93 & 6,93 & 0,43 & 35,90 \\
\hline C (серые) (gray) & 29,3 & 39,35 & 0,18 & 0,03 & 6,55 & 6,55 & 0,16 & 32,61 \\
\hline
\end{tabular}

\section{Геолого-технологическая классификация} руд Лисаковского месторождения

Геолого-технологическая классификация руд Лисаковского месторождения представлена в табл. 2. В каждой из групп выделены типы, по наличию дополнительных отличительных признаков - подтипы. Руды существующих типов содержат от 30 до 49 \% железа и обладают различными магнитными свойствами.
В рудах выделяются три структурных вида: густоолитовые руды, сложенные преимущественно рудными оолитами (50-80 \%) с подчиненным количеством цемента и кварца; редкоолитовые руды, состоящие из рудных оолитов (менее 50 \%) с преобладанием цемента и свободного кварца; и мелкооолитовые цементированные руды.

Таблица 2. Геолого-технологическая классификация Лисаковского месторождения [4]

Table 2. Geological and technological classification of the Lisakovsky field [4]

\begin{tabular}{|c|c|c|c|c|c|c|c|c|c|c|c|c|}
\hline \multicolumn{3}{|c|}{$\begin{array}{l}\text { Характеристика руд } \\
\text { Ore characteristics }\end{array}$} & \multicolumn{2}{|c|}{$\begin{array}{l}\text { Массовая доля, \% } \\
\text { Mass fraction, } \%\end{array}$} & \multicolumn{6}{|c|}{$\begin{array}{l}\text { Классы крупности, мм } \\
\text { Size classes, mm }\end{array}$} & \multicolumn{2}{|c|}{$\begin{array}{l}\text { Концентрат } \\
\text { Concentrate }\end{array}$} \\
\hline \multirow[b]{2}{*}{ 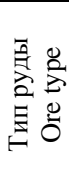 } & \multirow[b]{2}{*}{ 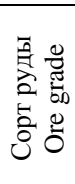 } & \multirow[b]{2}{*}{$\begin{array}{c}\text { Структурно-текстурная } \\
\text { и минералогическая } \\
\text { Structural-textural and } \\
\text { mineralogical }\end{array}$} & \multirow[b]{2}{*}{$\mathrm{Fe}$} & \multirow[b]{2}{*}{ 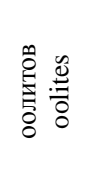 } & \multicolumn{2}{|c|}{1,6} & \multicolumn{2}{|c|}{$-0,6+0,3$} & \multicolumn{2}{|c|}{$-0,3+0,15$} & \multirow[b]{2}{*}{ 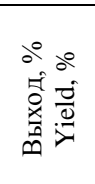 } & \multirow[b]{2}{*}{ 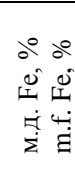 } \\
\hline & & & & & 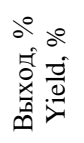 & 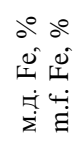 & 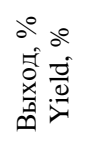 & 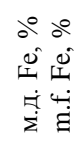 & 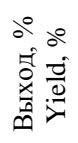 & 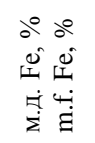 & & \\
\hline \multirow{2}{*}{1} & $1-1$ & \begin{tabular}{|l|} 
Рыхлые густоолитовые \\
Loose dense oolitic
\end{tabular} & $42-49$ & $60-85$ & $0-7$ & $27-46$ & $35-65$ & $44-49$ & 4-24 & $38-47$ & - & - \\
\hline & $1-2$ & $\begin{array}{l}\text { Крупно-средне-оолитовые } \\
\text { Large-medium oolitic }\end{array}$ & $40-42$ & $55-75$ & $0-10$ & $25-44$ & $33-60$ & $42-48$ & 4-24 & $35-46$ & $65-85$ & $49-51$ \\
\hline \multirow{3}{*}{2} & $2-3$ & \begin{tabular}{|l|} 
Рыхлые густо- олитовые \\
средне-мелкоолитовые \\
Loose dense oolitic \\
medium-small oolitic
\end{tabular} & $38-40$ & $50-70$ & $0-10$ & $23-44$ & $29-57$ & $33-47$ & $6-31$ & $33-45$ & $60-75$ & $48-50$ \\
\hline & $2-4$ & $\begin{array}{l}\text { Рыхлые редкоолитовые } \\
\text { Loose rare oolitic }\end{array}$ & $34-38$ & $40-65$ & $0-15$ & $21-42$ & $24-52$ & $32-46$ & $7-38$ & $27-44$ & $53-70$ & $47-49$ \\
\hline & $2-7$ & $\begin{array}{l}\text { Средне-мелкоолитовые } \\
\text { Medium-small oolitic }\end{array}$ & $30-34$ & $25-60$ & $0-10$ & $19-42$ & $11-50$ & $20-43$ & $8-48$ & $20-42$ & $40-65$ & $44-47$ \\
\hline \multirow{3}{*}{3} & $3-5$ & $\begin{array}{l}\text { Редкоолитовые } \\
\text { Rare oolitic }\end{array}$ & $34-38$ & $40-65$ & $10-45$ & 24-47 & $19-15$ & $38-46$ & $3-20$ & $30-46$ & $45-70$ & $47-50$ \\
\hline & $3-6$ & $\begin{array}{l}\text { Мелкоолитовые } \\
\text { Small-oolitic }\end{array}$ & $34-38$ & $30-60$ & $10-45$ & $22-46$ & $12-47$ & $21-45$ & $3-35$ & $25-45$ & $45-60$ & $44-47$ \\
\hline & $3-8$ & $\begin{array}{l}\text { Редко- и мелкоолитовые } \\
\text { Rare small oolitic }\end{array}$ & $30-34$ & $25-60$ & $10-45$ & $19-45$ & $9-44$ & $17-45$ & $3-35$ & $15-43$ & $30-60$ & $42-47$ \\
\hline
\end{tabular}


Анализируя оолитовые руды Лисаковского месторождения, следует отметить, что руда I типа имеет в основном крупно- и среднеоолитовую форму с минимальным количеством сростков оолитов с примесями и может хорошо разделяться при обогащении.

Руда II типа представляет собой крупно-, средне- и мелкооолитовый вид, включает значительное количество сростков оолитов с примесями, что затрудняет в процессе обогащения отделение примесей.

Оолитовая железная руда III типа представляет собой скопления относительно крупных, средних и мелких оолитов с большим количеством примесей, которые образуют прочные сростки с оолитами, что требует больших затрат на измельчение и сортировку в процессе подготовки руды к обогащению.

Богатый железорудный концентрат содержит 59,5-60 \% железа, 6,0-6,5 \% диоксида кремния, немагнитная фракция - 7,0-9,5 \%, при этом содержание железа в хвостах обогащения менее 23,0 \%.
Из руд II и III типа, содержащих до 40,0 \% железа, получен гравитационно-магнитный концентрат, содержащий 57,8 \% железа, 10,7-11,0 \% диоксида кремния и 12,1-12,5 \% гидратной влаги.

\section{Гранулометрический анализ}

оолитовых руд и концентратов

Гранулометрический анализ руд показывает: руды I и II сорта состоят на $80 \%$ из фракции $-0,63+0,16 \mathrm{Mm;}$ количество основных фракций в руде III сорта понижается до $60 \%$, а количество фракций более 0,63 и менее 0,16 мм повышается суммарно с 20 до $40 \%$. Железорудный концентрат после обогащения содержит более $95 \%$ фракции -0,63 +0,16 мм [3, 4].

Характер изменения качества оолитовых лисаковских железных руд I, II и III типов и концентрата гравитационного и магнитного обогащения представлен в табл. $3[3,4,6]$.

Таблица 3. Качественный состав Лисаковской руды и концентрата

Table 3. Qualitative composition of Lisakovsky ore and concentrate

\begin{tabular}{|c|c|c|c|c|c|c|c|c|c|c|c|}
\hline \multicolumn{2}{|c|}{ Крупность/Coarseness } & \multicolumn{9}{|c|}{ Химический состав/Chemical composition, \% } & \multirow{2}{*}{$\frac{\mathrm{P}}{\mathrm{Fe}} \cdot 100, \%$} \\
\hline $\begin{array}{l}\text { фракция, мм } \\
\text { fraction, } \mathrm{mm}\end{array}$ & $\begin{array}{c}\text { Выход, \% } \\
\text { Yield, \% }\end{array}$ & $\begin{array}{l}\mathrm{Fe}_{\text {общ }} \\
\mathrm{Fe}_{\text {gen }}\end{array}$ & $\mathrm{FeO}$ & $\mathrm{SiO}_{2}$ & $\mathrm{Al}_{2} \mathrm{O}_{3}$ & $\mathrm{CaO}$ & $\mathrm{MgO}$ & $\mathrm{MnO}$ & $\mathrm{S}$ & $\mathrm{P}$ & \\
\hline \multicolumn{12}{|c|}{ I тип руды/I type of ore } \\
\hline$>0,63$ & 16,2 & 24,38 & 12,59 & 48,49 & 2,16 & 1,19 & 1,31 & 0,35 & 0,030 & 0,27 & 1,108 \\
\hline $0,315 \ldots 0,63$ & 42,8 & 45,56 & 2,05 & 16,63 & 4,65 & 1,98 & 1,04 & 0,30 & 0,024 & 0,74 & 1,578 \\
\hline $0,16 \ldots 0,315$ & 34,1 & 33,93 & 2,24 & 39,31 & 2,82 & 1,49 & 1,14 & 0,28 & 0,027 & 0,48 & 1,415 \\
\hline$<0,16$ & 6,9 & 30,70 & 0,50 & 45,59 & 2,49 & 1,98 & 1,14 & 0,26 & 0,027 & 0,39 & 1,270 \\
\hline общ/gen & 100 & 37,14 & 3,72 & 31,52 & 3,47 & 1,68 & 1,12 & 0,30 & 0,026 & 0,55 & 1,425 \\
\hline \multicolumn{12}{|c|}{ II тип руды/II type of ore } \\
\hline$>0,63$ & 14,9 & 19,58 & 4,02 & 53,49 & 2,53 & 0,27 & 0,77 & 0,15 & 0,036 & 0,28 & 1,430 \\
\hline $0,315 \ldots 0,63$ & 26,2 & 21,31 & 2,41 & 56,92 & 2,43 & 0,37 & 1,06 & 0,21 & 0,020 & 0,31 & 1,408 \\
\hline $0,16 \ldots 0,315$ & 52,2 & 31,69 & 2,81 & 38,43 & 3,34 & 0,37 & 1,06 & 0,21 & 0,023 & 0,51 & 1,608 \\
\hline$<0,16$ & 6,7 & 18,24 & 3,22 & 52,95 & 2,24 & 0,74 & 0,87 & 0,19 & 0,023 & 0,22 & 1,205 \\
\hline общ/gen & 100 & 26,26 & 2,91 & 46,49 & 2,91 & 0,38 & 1,00 & 0,20 & 0,024 & 0,40 & 1,502 \\
\hline \multicolumn{12}{|c|}{ III тип руды/III type of ore } \\
\hline$>0,63$ & 28,3 & 29,56 & 0,4 & 39,18 & 4,06 & 0,74 & 1,25 & 0,23 & 0,020 & 0,43 & 1,455 \\
\hline $0,315 \ldots 0,63$ & 27,7 & 37,42 & 0,6 & 29,11 & 3,05 & 0,74 & 1,25 & 0,23 & 0,023 & 0,50 & 1,336 \\
\hline $0,16 \ldots 0,315$ & 31,2 & 46,74 & 0,4 & 11,58 & 4,53 & 0,37 & 1,35 & 0,22 & 0,020 & 0,70 & 1,297 \\
\hline$<0,16$ & 12,8 & 37,02 & 1,41 & 29,39 & 3,82 & 0,74 & 1,16 & 0,19 & 0,026 & 0,48 & 1,297 \\
\hline общ/gen & 100 & 38,05 & 0,58 & 26,53 & 3,90 & 0,62 & 1,27 & 0,22 & 0,022 & 0,54 & 1,353 \\
\hline \multicolumn{12}{|c|}{ Концентрат/Concentrate } \\
\hline$>0,63$ & 4,34 & 41,44 & 7,7 & 20,05 & 3,49 & 0,74 & $\mathrm{H} / \mathrm{o} / \mathrm{n} / \mathrm{d}$ & 0,38 & 0,017 & 0,503 & 1,214 \\
\hline $0,315 \ldots 0,63$ & 62,42 & 46,88 & 1,75 & 11,07 & 4,30 & 0,74 & $\mathrm{H} / \mathrm{o} / \mathrm{n} / \mathrm{d}$ & 0,33 & 0,013 & 0,673 & 1,463 \\
\hline $0,16 \ldots 0,315$ & 32,74 & 48,32 & 1,15 & 9,51 & 4,61 & 0,74 & $\mathrm{H} / \mathrm{o} / \mathrm{n} / \mathrm{d}$ & 0,33 & 0,011 & 0,707 & 1,463 \\
\hline$<0,16$ & 0,5 & 38,80 & 1,75 & 25,15 & 3,21 & 0,74 & $0,36 /$ & 0,38 & 0,025 & 0,463 & 1,193 \\
\hline общ/gen & 100 & 47,07 & 1,81 & 11,02 & 4,36 & 0,74 & - & 0,33 & 0,013 & 0,676 & 1,451 \\
\hline
\end{tabular}

Руды I и II сорта по гранулометрическому составу состоят в основном (до $80 \%$ ) из фракции $-0,63+0,16$ мм. В руде III сорта количество основных фракций понижается до $60 \%$, а количество фракций более 0,63 и менее 0,16 мм повышается суммарно до 40 \% [2-4].

Результаты магнитной сепарации руд I и III сорта в лабораторных условиях показывают, что более $95 \%$ железорудного концентрата содержится во фракции $0,63+0,16$ мм, руда II типа всех фракций содержит менее $30 \%$ и ее можно не обогащать, оставив в залежи или переместив в хвостохранилище.

В руде I, III типов содержится менее $30 \%$ железа во фракциях более 0,63 мм, поэтому необходимо провести предварительную сортировку руд I и III для удаления фракции более 0,63 мм [7-9].
Учитывая повышенную влажность руды, практически сортировку можно создать на грохотах с размером ячейки сита 3 (5) мм. Предварительное грохочение позволяет удалить $17 \%$ руды I типа, $28 \%$ руды III типа. Если руду II типа удалить из общего процесса обогащения, то общее исключение руд крупнее 1,0 мм из обогащения составит 40,5 \% общей массы.

Содержание тонких фракций менее 0,16 мм в рудах I-III типов составляет 8,7 и $12 \%$ соответственно. Расчеты показывают, что общее количество мелочи в исходной руде составит около $10 \%$.

Расчеты лабораторных исследований показывают, что предварительное удаление указанных фракций руды позволит повысить эффективность процесса обогащения [1]. 
Результаты исследований электронной микроскопии, проведенных авторами, показывают, что зерна оолитов имеют сложную структуру: часть зерен имеет оболочковую структуру, часть оолитов представлены смесью зерен различных минералов размером менее 50 микрон, поэтому для эффективного выделения железорудного концентрата необходимо измельчение.

Содержание железа в концентрате повышается за счет фракции $-0,63+0,16$ мм. Другие фракции руды I-III типа имеют пониженное содержание и их присутствие снижает качество готового концентрата.

Окись железа в рудах и концентрате находится ниже уровня 4,0 \%, повышаясь во фракции крупнее 0,63 мм руды I типа до 12,59 \%. Целесообразно определить магнитные свойства указанных фракций и провести сепарацию при магнитной индукции порядка 0,1 тесла.

Повышенное содержание кремнезема находится во фракциях руды крупнее 0,63 мм и менее 0,16 мм. В процессе обогащения руды содержание кремнезема во всех фракциях концентрата понижается.

Количество глинозема во всех фракциях руд I-III типов от 2,16 \% (фракция >0,63, руда І типа) до 4,65\% (фракция 0,315-0,63, руда I типа), в процессе обогащения повышается до 5,26 \%.

Оксид кальция в руде I типа составляет 1,98 \% (фракция $0,315-0,63$ ) и понижается до 0,74 \% в концентрате. Это свидетельствует о том, что окись кальция в значительной мере сосредоточена вне оолитов. Можно предположить, что кальций связан с фосфором, образуя химические соединения типа апатит.

Содержание окиси магния в концентрате понижается до 0,36 \% с 1,00-1,21\% в исходной руде.

Величина закиси марганиа во всех сравниваемых материалах находится на одном уровне.

Количество серы в концентрате по сравнению с рудами I-III типа снижается на 30 \% [8-11].

Содержание фосфора в процессе обогащения повышается по сравнению с содержанием в рудах I-III типов. Отмечено неравномерное распределение фосфора по фракциям руды. Меньшая концентрация фосфора содержится во фракциях <0,16 и крупнее 0,63 мм, во фракциях -0,63+0,16 мм содержится повышенное его количество.

Представленная информация свидетельствует о том, что оолиты всех трех типов руд представляют собой смесь железосодержащих зерен в обрамлении обломков, не содержащих железо. Ярко выраженной зональной структуры зерен не обнаружено. Отмечена высокая трещиноватость оолитов, что обеспечивает минимальные затраты при измельчении руд. Для определения требуемой крупности измельчения - менее 0,074 или 0,040 мм - необходимо провести дополнительные исследования [12-18].

Из представленного качества концентрата, полученного последовательно произведенными гравитационным и магнитным методами, следует, что гравитационно-магнитный концентрат представляет собой смесь оолитов крупных, средних, мелких размеров с кварцем и примесями руды, наличие которых свиде- тельствует о том, что качество обогащения требуется улучшить.

Ярко выраженной зональной структуры зерен не обнаружено. Отмечено, что оолиты обладают высокой трещиноватостью, что обеспечивает минимальные затраты при измельчении руд [19, 20].

Рудные запасы месторождения подразделяются на 26 рудных залежей, разделенных между собой условными границами. В настоящее время разрабатывается главная залежь (участки 1-3) со средней массовой долей железа 38,2 \%, мощность уступов 12-13 м. Массовая доля железа в рудах колеблется в широком диапазоне - от 14,5 до 48 \% - при средней массовой доле серы $0,03 \%$ и фосфора 0,5-0,7 \%. Мощность вскрышного слоя 1-2 м в центральной части и до 20 м на периферии.

В ходе проведения лабораторных исследований мы впервые проанализировали содержание редких металлов и рассеянных элементов в рудах и концентратах.

Результаты распределения цветных, редких металлов и рассеянных элементов в процессе магнитного обогащения представлены в табл. 4 [3, 4].

Анализ результатов лабораторных исследований проб из хвостов обогащения показал, что содержания металлов: Sr, Ti, Zr, Ga, Ce, Ba, Be, Li, Cd, Y и Co, ниже кларкового значения в литосфере. Содержания $\mathrm{Mn}, \mathrm{Pb}, \mathrm{As}, \mathrm{W}, \mathrm{Cr}, \mathrm{Ni}, \mathrm{Bi}, \mathrm{Mo}, \mathrm{V}, \mathrm{Cu}$ выше среднего значения содержания металлов в литосфере. Так, содержания $\mathrm{Cu}, \mathrm{Ag}$ и $\mathrm{W}$ превышают в 5, 9 и 12,5 раз кларковые содержания.

Содержания Ti, Zr, Ga, Ge, Bi, Be, Nb, Sn, Li, Y, Sr ниже кларкового значения в литосфере и их распределение не рассматривается, т. к. не имеет практического значения.

Превышают среднее значения в литосфере $\mathrm{Sc}, \mathrm{Mn}$, $\mathrm{Pb}, \mathrm{W}, \mathrm{Cr}, \mathrm{Ni}, \mathrm{Ba}, \mathrm{Mo}, \mathrm{V}, \mathrm{Cd}, \mathrm{Cu}, \mathrm{Zn}, \mathrm{Ag}$, в том числе, в 5 раз и более превышают значения металлы: $\mathrm{Mn}, \mathrm{Pb}$, W, Cr, Ba, Cu, Zn, Ag [4].

\section{Выводы}

1. Исследования гранулометрического состава руд показывают, что руды I и II сорта состоят в основном (до $80 \%$ ) из фракции $-0,63+0,16$ мм. В руде III сорта количество основных фракций понижается до $60 \%$, а количество фракций $+0,63$ и 0,16 мм повышается суммарно до $40 \%$.

2. Анализ результатов лабораторных исследований проб из хвостов обогащения показал, что содержания металлов: $\mathrm{Sr}, \mathrm{Ti}, \mathrm{Zr}, \mathrm{Ga}, \mathrm{Ce}, \mathrm{Ba}, \mathrm{Be}, \mathrm{Li}, \mathrm{Cd}$, $\mathrm{Y}$ и $\mathrm{Co}$, ниже кларкового значения в литосфере. Содержания $\mathrm{Mn}, \mathrm{Pb}, \mathrm{As}, \mathrm{W}, \mathrm{Cr}, \mathrm{Ni}, \mathrm{Bi}, \mathrm{Mo}, \mathrm{V}, \mathrm{Cu}$ выше среднего значения содержания металлов в литосфере. Так, содержания $\mathrm{Cu}, \mathrm{Ag}$ и $\mathrm{W}$ превышают в 5, 9 и 12,5 раз кларковые содержания. В отдельных случаях $\mathrm{Mn}, \mathrm{Pb}$ и Вi превышают средние значения в 33, 55 и 59 раз. Выявить закономерности связи повышения содержаний редких металлов и рассеянных элементов, связанных с процессами магнитного обогащения, не удалось. 
Таблица 4. Результаты распределения цьветных, редких и рассеянных металлов в процессе магнитного обогащения

Table 4. Results of distribution of non-ferrous, rare and scattered metals in magnetic enrichment

\begin{tabular}{|c|c|c|c|c|c|c|c|c|c|c|c|c|c|c|c|c|c|c|c|c|c|c|c|c|c|}
\hline 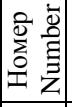 & $\mathrm{Sc}$ & $\mathrm{P}$ & $\mathrm{Sb}$ & $\mathrm{Mn}$ & $\mathrm{Pb}$ & $\mathrm{Ti}$ & $\mathrm{Zr}$ & As & $\mathrm{Ga}$ & W & $\mathrm{Cr}$ & $\mathrm{Ni}$ & $\mathrm{Ge}$ & $\mathrm{Bi}$ & $\mathrm{Ba}$ & $\mathrm{Be}$ & $\mathrm{Nb}$ & Mo & $\mathrm{Sn}$ & V & $\mathrm{Li}$ & $\mathrm{Cd}$ & $\mathrm{Cu}$ & $\mathrm{Yb}$ & Y \\
\hline 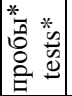 & \multicolumn{25}{|c|}{$\begin{array}{l}\Gamma / \mathrm{T} \\
\mathrm{g} / \mathrm{t}\end{array}$} \\
\hline 2 & 3 & 4 & \begin{tabular}{|l|}
5 \\
\end{tabular} & \begin{tabular}{|l|}
6 \\
\end{tabular} & 7 & 8 & 9 & 10 & 11 & 12 & 13 & 14 & 15 & 16 & 17 & 18 & 19 & 20 & 21 & 22 & 23 & 24 & 25 & 26 & 27 \\
\hline 3* & 2 & 500 & 15 & \begin{tabular}{|l|}
1500 \\
\end{tabular} & 15 & 600 & 25 & 1200 & 5 & 5 & 8 & 14 & 15 & 16 & 17 & 18 & 19 & 20 & 21 & 22 & & 24 & 25 & & \\
\hline 4* & 8 & 600 & 15 & 00 & 15 & 500 & 0 & 300 & 1 & 5 & 25 & 15 & 2 & 4 & 100 & 3 & & & & 5 & & 5 & 00 & 1 & 8 \\
\hline $5^{*}$ & 4 & 300 & 15 & 000 & 20 & 800 & 3 & 500 & 4 & 5 & 8 & 40 & 1. & 2 & 100 & 5 & & & & 100 & & & 0 & 1,5 & \\
\hline $6^{*}$ & 15 & 800 & 15 & 10000 & 25 & 1500 & 25 & 1000 & 25 & 5 & 15 & 12 & 1,5 & 2 & 100 & 0,4 & & & & 20 & & 5 & 20 & 1,5 & 6 \\
\hline 7 & 3 & 500 & 15 & 2500 & 25 & 1000 & 5 & 1000 & 8 & 5 & 10 & 0 & 3 & 2 & \begin{tabular}{|l|}
400 \\
\end{tabular} & 0,3 & & 5 & & 80 & & 5 & 00 & \begin{tabular}{|l|}
3 \\
\end{tabular} & 30 \\
\hline 8 & 20 & 600 & 15 & 8000 & 20 & 2500 & & 600 & 10 & 5 & & 25 & & 2,5 & \begin{tabular}{|l|}
100 \\
\end{tabular} & & & 3 & & 4 & & 5 & 00 & 1 & 8 \\
\hline 9 & 2 & 300 & 15 & 00 & 12 & 500 & 25 & 400 & 8 & 5 & & 40 & & 2 & & & & & & & & & 0 & 3 & 30 \\
\hline 10 & 20 & 800 & 15 & 8000 & 20 & 1500 & 80 & 600 & 8 & 5 & \begin{tabular}{|l|}
12 \\
\end{tabular} & \begin{tabular}{|l|l|}
15 \\
\end{tabular} & 1,5 & 2 & 100 & 0,3 & 4 & 5 & $\varepsilon$ & 80 & 1 & 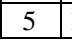 & 120 & 1 & 10 \\
\hline \multicolumn{26}{|c|}{ Значение кларка/Clark value } \\
\hline & 6 & 800 & -1 & 900 & 16 & 6000 & 200 & 5 & 15 & 1 & & 80 & 7 & 0,2 & 500 & 6 & 10 & 3 & 40 & 150 & 65 & 0,5 & 100 & - & 28 \\
\hline \multicolumn{26}{|c|}{$\begin{array}{l}\text { Отношение содержания элементов в пробах к кларковому содержанию } \\
\text { Ratio of the content of elements in samples to the clarke content }\end{array}$} \\
\hline 3 & 0,33 & 0,63 & - & 1,67 & 0,94 & \begin{tabular}{|l|l|}
0,10 \\
\end{tabular} & 0,13 & 240,0 & 0,33 & 5,00 & 0,04 & \begin{tabular}{|l|l|}
0,19 \\
\end{tabular} & 0,29 & 20,00 & 0,20 & 0,05 & 0,40 & 1,00 & 0,15 & 0,17 & 0,15 & 10,0 & 1,00 & - & 0,29 \\
\hline 4 & 1,33 & 0,75 & - & 8,89 & 0,94 & 0,25 & 0,50 & 60,00 & 1,00 & 5,00 & 0,13 & 50 & & & 0,20 & 0,0 & 0,30 & 2,00 & 0,10 & 0 , & & 10,0 & 2,00 & - & 0,5 \\
\hline 5 & 0,67 & 0,38 & - & 1,11 & 1,25 & 0,13 & 0,1 & 100,0 & 0,27 & 5,00 & 0,04 & 0,15 & & & 0,20 & 0, & 0,40 & 1,33 & & & & 10,0 & 1,20 & - & 0,2 \\
\hline 6 & 2,50 & 1,00 & - & 11,11 & 1,56 & 0,25 & 0,13 & 200,0 & 1,67 & 5,00 & 0,08 & 0,75 & & 10, & 0,80 & & 0,60 & 1,67 & & & 51 & 10,0 & 6,00 & - & 1,0 \\
\hline 7 & 0,50 & 0,63 & - & 2,78 & 1,56 & 0,17 & 0,0 & 200,0 & 0,53 & 5,00 & 0,05 & 0,31 & 0,21 & 12,50 & 0,20 & 0 , & 0,40 & 1,00 & 0,15 & 0,27 & 0,15 & 10,0 & 5,00 & - & 0,2 \\
\hline 8 & & 0,75 & - & 8,89 & 1,25 & 0,42 & 0,10 & 120,0 & 0,67 & 5,00 & 0,06 & 0,50 & 0,21 & 0,00 & 0,20 & 0,05 & 0,40 & 1,33 & 0,10 & 0,53 & 0,15 & 10,0 & 6,00 & - & 1,0 \\
\hline 9 & 0,33 & 0,38 & \begin{tabular}{|l|}
- \\
\end{tabular} & 1,33 & 0,75 & 0,08 & 0,13 & 80,00 & 0,53 & 5,00 & 0,05 & \begin{tabular}{|l|l|}
0,19 \\
\end{tabular} & 0,21 & 10,00 & 0,20 & 0,05 & 0,40 & 1,67 & 0,20 & 0,53 & 0,15 & 10,0 & 1,20 & - & 0,3 \\
\hline 10 & 3,33 & 1,00 & & 8,89 & 1,25 & 0,25 & 0,40 & 120,0 & 0,53 & 5,00 & 0,06 & 0,63 & 0,21 & 10,00 & 0,30 & 0,05 & 0,30 & 1,33 & 0,06 & 0,53 & 0,15 & \begin{tabular}{|l|l|}
4,00 \\
\end{tabular} & 4,00 & - & 1,43 \\
\hline
\end{tabular}

*Примечание: проба 3 - концентрат магнитной сепарации фракции -5+3 мм; проба 4 - хвосты магнитной сепарации фракиии -5+3 мм; проба 5 - концентрат магнитной сепарации фракиии -3+1 мм; проба 6 - хвосты магнитной сепарации фракции -3+1 мм.

*Note: sample 3 - magnetic separation concentrate of fraction -5+3 mm; sample 4 - tails of magnetic separation of fraction $-5+3 \mathrm{~mm}$; sample 5 - magnetic separation concentrate of fraction $-3+1 \mathrm{~mm}$; sample 6 - magnetic separation tails of $-3+1$ mm fraction.

\section{СПИСОК ЛИТЕРАТУРЫ}

1. Оолитовые железные руды Лисаковского месторождения Кустанайской области // под ред. И.П. Бардина. - М.: Изд-во «Академия наук», 1962. - 234 с.

2. Каскатаева К.Б., Кряжева Т.В., Аскарова Н.С. Минеральный состав руд Лисаковского месторождения // Интеграция науки, образования и производства - основа реализации Плана нации: Международная научно-практическая конференция. (Сагиновские чтения № 11). - Караганда: КарГТУ, 2019. - Ч. 3. C. $287-290$.

3. Каскатаева К.Б., Каскатай А.М., Кряжева Т.В. Характеристика оолитовых руд Лисаковского месторождения // Проблемь геологии и освоения недр: XXIV Международный научный симпозиум студентов и молодых ученых имени академика М.А. Усова. - Томск: ТПУ, 2020. - С. 205-207.

4. Результаты изучения содержания редких металлов в рудах Лисаковского месторождения / К.Б. Каскатаева, Т.В. Кряжева, В.В. Дьяконов, А.В. Садчиков, А. Каскатай // Управление инновационными процессами в условиях модернизации образования и науки: II Международная научно-практическая конференция. - Мюнхен, Германия, 2020. - С. 225-232.

5. Бекмухаметов А.Е. Металлогения экзогенных руд железа Торгайского прогиба и перспективы промышленного освоения их Лисаковским ГОКом. - Алматы: Гылым, 2003. - 256 с.

6. Исследования лисаковских железных руд / Т.В. Кряжева, Г.Ж. Досетова, К.Т. Шынбергенова, Л.А. Максютин // Повышение качества образования, современные инновации в науке и производстве: Сборник трудов Международной научнопрактической конференции. - Экибастуз: КузГТУ, 2018. C. 389-397.

7. Рева И.В., Сорокина А.М. Геохимические особенности оолитовых железняков Лисаковского месторождения (Торгайский прогиб, Казахстан) // Проблемы геологии и освоения недр: труды XXIII Международного симпозиума имени академика М.А. Усова студентов и молодых ученых, посвященного 120-летию со дня рождения академика К.И. Сатпаева, 120-летию со дня рождения профессора К.В. Радугина. Томск: Изд-во ТПУ, 2019. - Т. 1. - С. 169-171.

8. Юрьев Б.П., Дудко В.А. Разработка экологически чистой технологии обогащения железных руд // Черная металлургия. Бюллетень научно-технической и экономической информации. - 2018. - № 10 (1426). - С. 35-45.

9. Saidung S., Starostin V.I., Prokofiev V.Y. Ore-forming fluids of Xishimen skarn iron deposit, China // Geology of Ore Deposits. 2017. - V. 59. - № 2. - P. 176-182.

10. Trushko V.L., Trushko O.V., Potemkin D.A. Provision of stability of development mining at Yakovlevo iron ore deposit // International Journal of Applied Engineering Research. - 2016. V. 11. - № 18. - P. 9248-9255.

11. Garnit H., Bouhlel S. Petrography, mineralogy and geochemistry of the late Eocene oolitic ironstones of the Jebel Ank, southern Tunisian atlas // Ore Geology Reviews. - 2017. - V. 84. - P. 134-153.

12. Process oriented characterization of oolitic iron concentrate during dephosphorisation by roasting and leaching / K. Ionkov, S. Gaydardzhiev, O. Gomes, R. Neumann, A. Correa de Araujo // IMPC $2016-28^{\text {th }}$ International mineral processing congress. Conferense proceedings. - Québec, Canada: Canadian Institute of Mining, Metallurgy and Petroleum, 2016. $-116 \mathrm{p}$.

13. Quast K.A review on the characterisation and processing of oolitic iron ores // Minerals Engineering. - 2018. - V. 126. - P. 89-100.

14. Potemkin D.A., Popov M.G., Trushko O.V. Examination and analysis of actual stability of mine workings at the Yakovlevsky iron ore deposit // Arpn journal of engineering and applied sciences. - 2018. - V. 13. - № 7. - P. 2490-2499.

15. Сорокина А.М., Рева И.В., Рудмин М.А. Минеральная форма редкоземельных элементов в морских ооидовых железняках // Минерально-сырьевая база алмазов, благородных и цветных 
металлов - от прогноза к добыче: Сборник тезисов докладов молодежной научно-образовательной конференции ЦНИГРИ. - М.: Центральный научно-исследовательский геологоразведочный институт цветных и благородных металлов, 2020. - C. $179-182$

16. Такишов А.А., Капсалямов Б.А., Шынбергенова К.Т. Техногенные отходы - как резерв минерально-сырьевого комплекса // Академик О.А. Байконуров и его вклад в развитие горного дела, науки и образования Казахстана: Материалы XII Международных Байконуровских чтений. - Жезказган, 2018. C. 378-383.

17. Bio-extraction of phosphorus from goethite ore with alkali addition / L. Zhang, S. Ankathi, M. Zhang, T. Eisele // Minerals engineering. - 2019. - V. 141. - P. 105850.

18. Kokal H.R., Farias J.M., Chop S.V. A roasting-leaching demonstration plant for removal of phosphorus from iron ore //
Hydrometallurgy 2008: Proceedings of the $6^{\text {th }}$ International Symposium. - Финикс, Аризона, 2008. - 431 р.

19. Дефосфорация лисаковского железорудного концентрата Л.А. Зайнуллин, В.Г. Карелин, А.Ю. Епишин, Д.А. Артов // Современные тенденции в области теории и практики добычи и переработки минерального и техногенного сырья. Материалы международной научно-практической конференции, приуроченной к 90-летию со дня основания института «Уралмеханобр». - Екатеринбург: ОАО «Уралмеханобр», 2019. С. 217-219.

20. Карелин В.Г., Зайнуллин Л.А., Епишин А.Ю. Кинетика высокотемпературной дегидратации лисаковского железорудного концентрата // Известия высших учебных заведений. Черная металлургия. - 2017. - Т. 60. - № 8. - С. 656-661.

Поступила 01.03.2021 2.

\section{Информация об авторах}

Каскатаева К.Б., докторант кафедры геологии и разведки месторождений полезных ископаемых Некоммерческого акционерного общества «Карагандинский технический университет».

Кряжсева T.B., кандидат геолого-минералогических наук, доцент кафедры геологии и разведки месторождений полезных ископаемых Некоммерческого акционерного общества «Карагандинский технический университет».

Cадчиков A.B., кандидат технических наук, старший преподаватель кафедры геологии и разведки месторождений полезных ископаемых Некоммерческого акционерного общества «Карагандинский технический университет».

Дьяконов В.B., доктор геолого-минералогических наук, профессор, заведующий кафедрой общей геологии и геологического картирования Российского государственного геологоразведочного университета им. Серго Орджоникидзе (МГРИ). 
UDC 553.31

\title{
CHARACTERISTICS OF ORES OF THE LISAKOVSKY DEPOSIT FOR THEIR COMPLEX PROCESSING
}

\author{
Kuralay B. Kaskataeva1, \\ aigakk@mail.ru
}

Tatyana V. Kryazheva1, kryazheva_@@mail.ru

Alexander V. Sadchikov ${ }^{1}$, a.sadchikov@kstu.kz

Viktor V. Dyakonov², mdf.rudn@mail.ru

1 Non-profit Joint Stock Company «Karaganda Technical University», 56, Nazarbayev avenue, Karaganda, 100027, Kazakhstan.

2 Sergo Ordzhonikidze Russian State Geological Exploration University (MGRI), 23, Miklukho-Maklay street, Moscow, 117997, Russia.

The relevance of the study is caused by the necessity to assess the possibility of associated extraction of non-ferrous, rare metals and scattered elements. The study is based on the results of analysis of samples of oolite ores from the western section of the field. In the course of research. The industrial types of iron ores of the deposit are studied, the distribution of rare metals by various industrial types, fractions of Lisakovsky iron ores and concentrates is considered

The aim of the research is to study the characteristics of the ores of the Lisakovsky deposit for their complex processing.

The object of research is the oolite ores of the Lisakovsky deposit.

Method. Laboratory studies of ores and concentrates of the Lisakovsky deposit were carried out. Granulometric analysis by types and grades of ores was carried out. Chemical composition of ores and concentrates by fractions was studied

Results. Studies of the granulometric composition of ores show that grade I and II ores consist mainly (up to $80 \%$ ) of a fraction of $-0,63+0,16 \mathrm{~mm}$. In grade III ore, the number of main fractions decreases to $60 \%$, and the number of fractions of $+0,63$ and $-0,16 \mathrm{~mm}$ increases to a total of $40 \%$. Analysis of the results of laboratory studies of samples from the enrichment tailings shown that the content of metals: Sr, Ti, Zr, Ga, CE, Ba, Ve, Li, Cd, Y and Co, is below the standard value in the lithosphere. The content of Mn, Pb, As, W, Cr, Ni, Bi, $\mathrm{Mo}, \mathrm{V}, \mathrm{Cu}$ is higher than the average value of the metal content in the lithosphere. Thus, the contents of $\mathrm{Cu}, \mathrm{Ag}$ and $\mathrm{W}$ exceed the clarke contents by 5,9 and 12.5 times, and the contents of $\mathrm{Mn}, \mathrm{Pb}$ and $\mathrm{Bi}$ are higher than the average values by 33,55 and 59 times.

\section{Key words:}

Productive thickness, oolites, ore types, phase composition, mineral composition,

internal structure of oolites, concentrate, granulometric composition, chemical composition.

\section{REFERENCES}

1. Bardin I.P. Oolitovye zheleznye rudy Lisakovskogo mestorozhdeniya Kustanayskoy oblasti [Oolite iron ores of the Lisakovsky district of the Kostanay region]. Moscow, Akademiya nauk Publ., 1962. 234 p.

2. Kaskataeva K.B., Kryazheva T.V., Askarova N.C. Mineralny sostav rud Lisakovskogo mestorozhdeniya [Mineral composition of the Lisakovsky Deposit ores]. Mezhdunarodnaya nauchnoprakticheskaya konferentsiya. Integratsiya nauki, obrazovaniya $i$ proizvodstva - osnova realizatsii Plana natsii [International scientific and practical conference. Integration of science, education and production is the basis for the implementation of the national Plan]. Karaganda, KarGTU Publ., 2019. pp. 287-290.

3. Kaskataeva K.B., Kaskatay A.M., Kryazheva T.V. Kharakteristika oolitovykh rud Lisakovskogo mestorozhdeniya [Characteristics of oolite ores of the Lisakovsky Deposit]. XXIV Mezhdunarodny nauchny simpozium studentov $i$ molodykh uchenykh imeni akademika M.A. Usova. Problemy geologii $i$ osvoeniya nedr [XXIV international scientific Symposium of students and young scientists named after academician M.A. Usov. Problems of Geology and development of mineral resources]. Tomsk, TPU Publ., 2020. pp. 205-207.

4. Kaskataeva K.B., Kryazheva T.V., Diakonovv V., Sadchikov A.V., Kaskatay A. Rezultaty izucheniya soderzhaniya redkikh metallov v rudakh Lisakovskogo mestorozhdeniya [Results of studying the content of rare metals in the ores of the Lisakovsky Deposit]. II
Mezhdunarodnaya nauchno-prakticheskaya konferentsiya. Upravlenie innovatsionnymi protsessami $v$ usloviyakh modernizatsii obrazovaniya i nauki [II international scientific and practical conference. Management of innovative processes in the conditions of modernization of education and science]. Munich, Germany, 2020. pp. 225-232.

5. Bekmukhametov A.E. Metallogeniya ekzogennykh rud zheleza Torgayskogo progiba i perspektivy promyshlennogo osvoeniya ikh Lisakovskim GOKom [Metallogeny of exogenous iron ores of the Torgay bend and prospects for their industrial development by Lisakovsky GOK]. Almaty, Gylym Publ., 2003. 256 p.

6. Kryazheva T.V., Dosetova G.Zh., Shynbergenova K.T., Maksyutin L.A. Issledovaniya lisakovskikh zheleznykh rud [Research of lisakovsky iron ores]. Povyshenie kachestva obrazovaniya, sovremennye innovatsii $v$ nauke $i$ proizvodstve [Improving the quality of education, modern innovations in science and production]. Ekibastuz, KuzGTU Publ., 2018. pp. 389-397.

7. Reva I.V., Sorokina A.M. Geokhimicheskie osobennosti oolitovykh zheleznyakov Lisakovskogo mestorozhdeniya (Torgayskiy progib, Kazakhstan) [Geochemical features of oolitic ironstones of the Lisakovsky birthplace (torgaysky deflection, Kazakhstan)]. Problemy geologii $i$ osvoyeniya nedr. Trudy XXIII Mezhdunarodnogo simpoziuma imeni akademika M.A. Usova studentov i molodykh uchenykh, posvyashchennogo 120-letiyu so dnya rozhdeniya akademika K.I. Saptaeva, 120-letiyu so dnya rozhdeniya professor K.V. Radugina [Problems of Geology and subsoil development. Proc. of the XXIII international Symposium 
named after academician M.A. Usov of students and young scientists, dedicated to the $120^{\text {th }}$ anniversary of the birth of academician K.I. Satpayev, the $120^{\text {th }}$ anniversary of the birth of Professor K.V. Radugin]. Tomsk, TPU Publ., 2019. pp. 169-171.

8. Yuriev B.P., Dudko V.A. Development of environmentally friendly technology for iron ore enrichment. Ferrous metallurgy. Bulletin of scientific, technical and economic information, 2018, no. 10 (1426), pp. 35-45. In Rus.

9. Saidung S., Starostin V.I., Prokofiev V.Y. Ore-forming fluids of Xishimen skarn iron deposit. China. Geology of Ore Deposits, 2017, vol. 59, no. 2, pp. 176-182.

10. Trushko V.L., Trushko O.V., Potemkin D.A. Provision of stability of development mining at Yakovlevo iron ore deposit. International Journal of Applied Engineering Re-search, 2016, vol. 11, no. 18, pp. 9248-9255.

11. Garnit H., Bouhlel S. Petrography, mineralogy and geochemistry of the late Eocene oolitic ironstones of the Jebel Ank, southern Tunisian atlas. Ore Geology Reviews, 2017, vol. 84, pp. 134-153.

12. Ionkov K., Gaydardzhiev S., Gomes O., Neumann R., Correa de Araujo A. Process oriented characterization of oolitic iron concentrate during dephosphorisation by roasting and leaching. IMPC 2016 - $28^{\text {th }}$ International mineral processing congress Conference proceedings. Québec, Canada, 2016. pp. 116-122.

13. Quast K. A review on the characterisation and processing of oolitic iron ores. Minerals Engineering, 2018, vol. 126, pp. 89-100

14. Potemkin D.A., Popov M.G., Trushko O.V. Examination and analysis of actual stability of mine workings at the yakovlevsky iron ore deposit. Arpn journal of engineering and applied sciences, 2018, vol. 13, no. 7, pp. 2490-2499.

15. Sorokina A.M., Reva I.V., Rudmin M.A. Mineralnaya forma redkozemelnykh elementov v morskikh ooidovykh zheleznyakakh [Mineral form of rare earth elements in marine ooid ironstones]. Sbornik tezisov dokladov I molodezhnoy nauchno-obrazovatelnoy konferentsii CNIGRI - Mineralno-syrevaya baza almazov, blagorodnykh $i$ tsvetnykh metallov - ot prognoza $k$ dobyche [Collection of abstracts of the I youth scientific and educational conference TsNIGRI - Mineral resource base of diamonds, precious and non-ferrous metals - from forecast to production].
Moscow, Central Scientific-Research Geological Exploration Institute of Non-ferrous and Noble Metals Publ., 2020. pp. 179-182.

16. Takishov A.A., Kapsalyamov B.A., Shynbergenova K.T. Tekhnogennye otkhody - kak rezerv mineralno-syryevogo kompleksa [Technogenic waste - as a reserve of mineral raw materials complex]. Materialy XII Mezhdunarodnykh Baykonurovskikh chteniy. Akademik O.A. Baykonurov i ego vklad $v$ razvitive gornogo dela, nauki $i$ obrazovaniya Kazakhstana [Materials of the XII international Baikonur readings. Academician O.A. Baikonurov and his contribution to the development of mining, science and education in Kazakhstan]. Zhezkazgan, JESU Publ., 2018. pp. 378-383.

17. Zhang L., Ankathi S., Zhang M., Eisele T. Bio-extraction of phosphorus from goethite ore with alkali addition. Minerals engineering, 2019, vol. 141. pp. 105850.

18. Kokal H.R., Farias J.M., Chop S.V. A roasting-leaching demonstration plant for removal of phosphorus from iron ore. Proceedings of the $6^{\text {th }}$ International Symposium. Phoenix, AZ, Hydrometallurgy Publ., 2008. pp. 431-438.

19. Zainullin L.A., Karelin V.G., Epishin A.Yu., Artov D.A. Defosforatsiya lisakovskogo zhelezorudnogo kontsentrata [Dephosphorization of lisakovsky iron ore concentrate]. Sovremennye tendentsii $v$ oblasti teorii $i$ praktiki dobychi $i$ pererabotki mineralnogo $i$ tekhnogennogo syrya. Materialy mezhdunarodnoy nauchno-prakticheskoy konferentsii, priurochennoy $k$ 90-letiyu so dnya osnovaniya instituta "Uralmekhanobr» [Current trends in the theory and practice of mining and processing of mineral and man-made raw materials. Materials of the international scientific and practical conference dedicated to the $90^{\text {th }}$ anniversary of the Foundation of the Institute «Uralmekhanobr»]. Ekaterinburg, JSC «Uralmekhanobr» Publ., 2019. pp. 217-219.

20. Karelin V.G., Zainullin L.A., Epishin A.Yu. Kinetics of hightemperature dehydration of lisakovsky iron ore concentrate. Proceedings of higher educational institutions. Ferrous metallurgy, 2017, vol. 60, no. 8, pp. 656-661. In Rus.

Received: 1 March 2021.

\section{Information about the authors}

Kuralay B. Kaskataeva, doctoral student, Non-profit Joint Stock Company «Karaganda Technical University». Tatyana V. Kryazheva, Cand. Sc., associate professor, Non-profit Joint Stock Company «Karaganda Technical University».

Alexander V. Sadchikov, Cand. Sc., senior lecturer, Non-profit Joint Stock Company «Karaganda Technical University».

Viktor V. Dyakonov, Dr. Sc., professor, head of the Department of General Geology and geological mapping, Sergo Ordzhonikidze Russian State Geological Exploration University (MGRI). 